\title{
COMPILATION OF GLACIER MAPS FOR SOME MOUNTAINS
}

\section{(Abstract)}

\author{
by
}

$\mathrm{Gu}$ Pei and Bu Jueying

(Lanzhou Institute of Glaciology and Geocryology, Academia Sinica, Peking, China)

\section{ABSTRACT}

Chinese Glacier Inventory is part of International Glacier Inventory, and glacier maps are important components of the glacier inventory.

Since 1979, we have completed glacier maps for Qilianshan, Altaishan, Tianshan and Pamier mountain systems one after another, about $40 \%$ of the whole work.

In order to improve the quality and accuracy of the maps, we fully considered the principles for the compilation of the International Glacier Inventory with due respect to the specific conditions in China as follows;

1. Materials and data.

Newly published aerial topographic maps of 1:50000 and 1:100000 are used as basic maps with aerial photographs as supplementary data for checking and correction.

2. Scale and projection.

According to the use of the glacial maps, the shape and size of the surveyed area and base data, the scale of the maps of drainage basins is fixed at 1:250000 and
1:400 000, with Gauss projection. For the distribution maps of glaciers and their geographic landscape and characteristics, and for coding key maps, scales of 1:1000000 and 1:2000 000 are used, respectively, and their projection is the normal, minimum-error, conformal, conical projection, with two standard parallels.

3. Synthesis and presentational method.

To show the location, type, shape, direction of movement and dependent drainage basin of glaciers is the most important task for the compilation of glacier inventory. Therefore, it is very necessary to carry out scientific summarization during compilation and to decide the acceptance or rejection of the surveyed features. In addition, the key elements of drainage basins, ridges, etc. are also given in detail.

The glacier map is a basic skeleton for the glacier inventory, giving important basic data for glaciological research and exploitation, as well as the utilization of the ice-snow resources, etc. 